\title{
Stereotactic amygdaloidotomy for aggressive behaviour
}

\author{
L. G. KILOH, R. S. GYE, R. G. RUSHWORTH, D. S. BELL, \\ AND R. T. WHITE \\ From the Psychiatric Research Unit, Callan Park Hospital, Rozelle, N.S.W. \\ and University of New South Wales, Kensington, N.S.W., Australia
}

SYNOPSIS Amygdaloidotomy was performed bilaterally on 15 and unilaterally on three patients exhibiting severe aggressive or self-mutilating behaviour. Nine subjects $(50 \%)$ were improved a year after operation; improvement was maintained in seven $(39 \%$ ) for periods ranging from 27 months to nearly six years. Four non-epileptic cases had convulsions during the period of review; one of them has a persistent mild hemiparesis dating from the postoperative period. There was a tendency for epileptics to respond better than non-epileptics and for mentally retarded patients to respond poorly, but none of the differences was statistically significant.

Studies involving stimulation and ablation of the amygdala in animals have demonstrated clearly that these structures, particularly their basolateral divisions, play an important part in the determination of aggressive behaviour (Kaada, 1965). In man it has been much more difficult to produce anger or rage by electrical stimulation of the amygdala, although this has been achieved by Heath et al. (1955), King (1961), and Sweet et al. (1969).

Early studies of the effects of amygdaloidotomy in man include those of Sawa et al. (1954), Chatrian and Chapman (1960), and Schwab et al. (1965).

Narabayashi et al. (1963) reported the results of amygdaloidotomy in 60 patients, 40 of whom were under 14 years of age. Thirty-nine of these operations were unilateral. The patients were described as irritable, excitable, and distractable; the older ones in particular were assaultive and destructive. A good immediate result was claimed in $51(85 \%)$ but follow-up of 40 of the 60 patients over periods of three to six and a half years (Narabayashi and Uno, 1966) showed sustained improvement in only $27(68 \%)$. Results in the older-that is, 11 to 35 years-patients were poorer than in the younger, only four of $13(31 \%)$ showing persisting benefit.

Heimburger et al. (1966) described 20 epileptics with episodic or constant hostility, aggressiveness, or destructiveness who were subjected to amygdaloidotomy. Behaviour improved dramatically in seven patients and markedly in a further nine, giving an improvement rate of $80 \%$. Two patients previously confined to institutions, presumably for life, were discharged and remained well adjusted on follow-up after two and a half years and eight months respectively.

Vaernet and Madsen (1970) reported 12 female patients aged 23 to 69 years showing 'violently aggressive behaviour with assaults on fellow patients and ward personnel, and/or a marked tendency towards self-mutilation'. After bilateral amygdaloidotomy there was a marked improvement in or disappearance of aggressive behaviour in all but one patient. Six of the patients were schizophrenics; in these, hallucinations persisted but lost much of their threatening character.

Balasubramaniam and Ramamurthi (1968) reported the results of amygdaloidotomy in 44 aggressive children and adults. Unfortunately, few details of the psychiatric state pre- and postoperatively are given, but in 16 there was complete or almost complete cessation of aggressive behaviour and some improvement was observed in a further 10-an overall improvement rate of $59 \%$. A later study of 100 


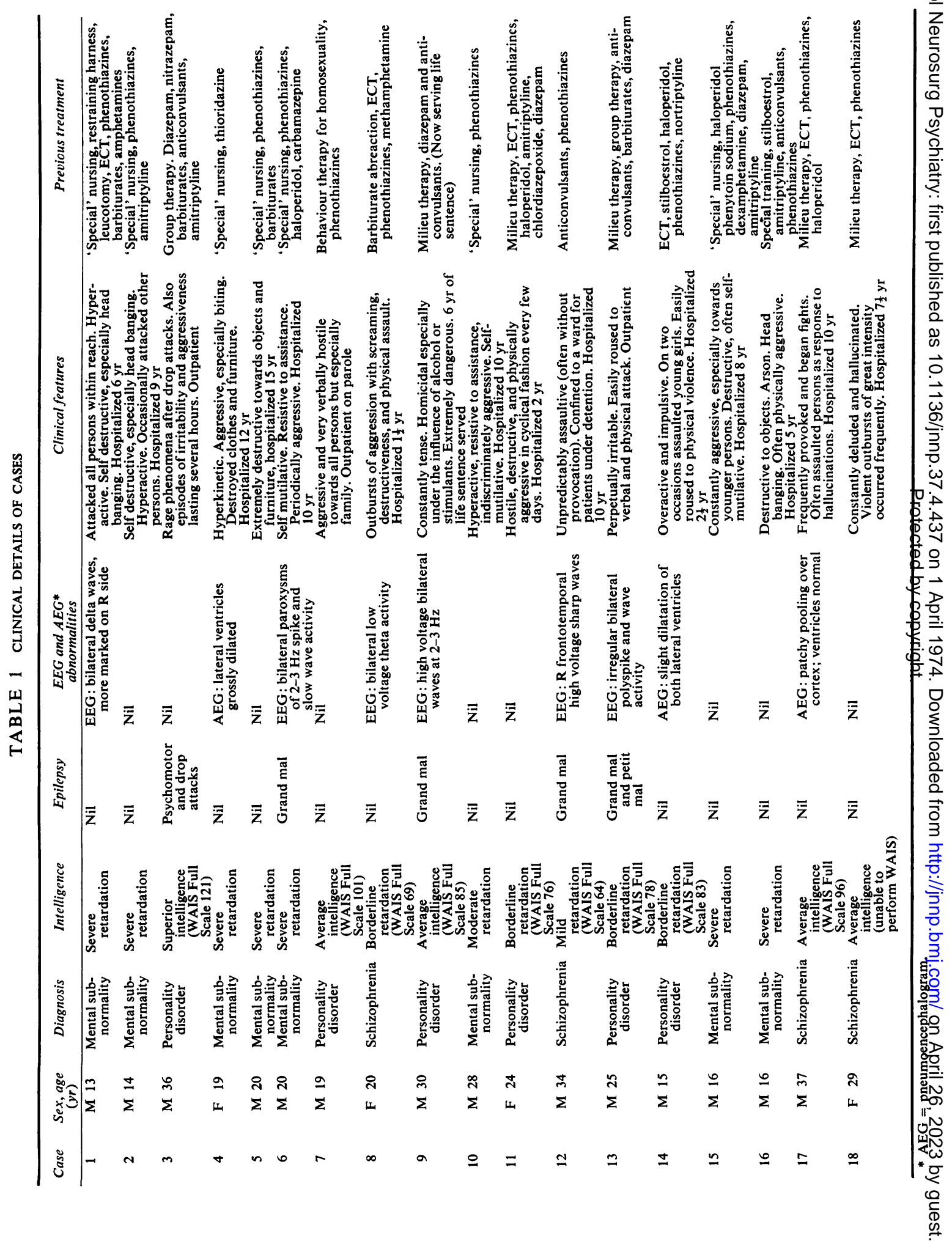


cases, including the original series of 44 , showed sustained improvement in 75 patients (Balasubramaniam and Ramamurthi, 1970).

Mempel (1971) described a series of 16 cases; 13 exhibited irritability and aggressive behaviour, two were depressed, and one had mixed symptoms. Thirteen were epileptic. After amygdaloidotomy Mempel reported a significant reduction in irritability, aggressiveness, and depression in all but one case. He also observed a reduced frequency and even relief of epileptic attacks in some patients. The period of postoperative observation varied from 2 to 15 months.

\section{METHODS}

Patients with aggressive behaviour of an incapacitating degree were referred to the Psychiatric Research Unit from psychiatric hospitals and units in New South Wales for consideration of amygdaloidotomy. The final decision to operate was taken by a committee of four clinicians. Brief clinical details of the patients and of the pneumoencephalographic and electroencephalographic findings are given in Table 1.

OPERATIVE TECHNIQUE All the operations were performed under general endotracheal anaesthesia using a Leksell stereotactic frame. It was intended that each patient would have a bilateral amygdaloidotomy, the operation being carried out in two stages four weeks apart. In three cases, only unilateral operations were carried out (see Table 2). Case 3 responded so dramatically to the unilateral procedure that the proposed second stage was considered unnecessary. Case 4 had dilatation and distortion of the left temporal horn of her lateral ventricle which prevented localization of the amygdaloid nucleus, and there was a technical failure in case 6 during the first stage of the procedure, which was abandoned.

The amygdaloid target was determined using the data of Baird et al. (1960), the intended centre of the lesion being placed $5 \mathrm{~mm}$ medial to the medial border of the lateral cleft.

In the first 12 patients, the temporal horn was outlined by the contrast medium iophendylate, and the lesion was made with a bipolar radiofrequency heat generator (Leksell) at $60-65^{\circ} \mathrm{C}$ for 30 seconds. In the last six patients of the series, the temporal horn was outlined by air and the lesion made with a Cooper cryoprobe at $-70^{\circ} \mathrm{C}$ for three minutes in cases 13 , 14 , and 15 and at $-120^{\circ} \mathrm{C}$ for three minutes in cases 16,17 , and 18 . In all cases the iophendylate or air was introduced into the lateral ventricle through a burr hole made at the coronal suture $4 \mathrm{~cm}$ from the midline. The same burr hole was then employed for depth recording and making the lesion.

POLYGRAPHY AND DEPTH RECORDINGS Polygraphic recording of autonomic activity at rest and in response to various stimuli was carried out before and after operation using an Offner Type $R$ Dynograph with the appropriate Offner/Beckman couplers and displayed on a 16-channel Offner Type TC electroencephalograph. The electroencephalogram (EEG), electrocardiogram, galvanic skin response, skin potential, and electrogastrogram were recorded using silver/silver chloride electrodes and the beatto-beat pulse rate with a cardiotachometer coupler.

The patient lay on a trolley in a quiet room. The preparation took up to one hour and in this time most patients became drowsy and appeared to become relaxed. A 10-minute resting (basal) record was obtained. A few days later this was repeated and followed by an habituation record-that is, the responses to a programmed series of 20 sound stimuli at-random intervals using the procedure described by Lader and Wing (1966). After this was completed, the experimenter approached the patient and at intervals of one minute made a series of actions designed to arouse the patient's concern, commencing with holding a syringe and needle in view of the patient, then preparing for an injection, and finally just stopping short of inserting the needle (response to menace).

At operation the same variables were recorded while depth electrography and electrical stimulation of the brain were carried out using a bipolar stainless steel electrode with gold-plated tips. This was inserted along the track to be taken by the lesionproducer. Recordings were made at the cerebral cortex and at various levels down to the amygdaloid nucleus. After electrography electrical stimulation was carried out using trains of $50 \mathrm{~Hz}$ bipolar electric pulses varying in duration from one to five seconds with a maximum peak amplitude of $5 \mathrm{~mA}$.

Basal autonomic activity was again recorded seven days after operation on each side and the basal, habituation and 'response to menace' recordings were repeated at between three months and one year later.

It is of some interest that one of our patients (case 15) had a typical grand mal seizure at the instant the Leksell cannula reached its target point in the left amygdaloid nucleus.

OBSERVATIONS The facilities for polygraphy were not available for case 1 or before the first operation in case 2 . Of the remainder, 11 patients were coopera- 
TABLE 2

RESULTS OF FOLLOW-UP

\begin{tabular}{|c|c|c|c|c|c|c|c|}
\hline \multirow{3}{*}{$\begin{array}{c}\text { Case } \\
\text { no. }\end{array}$} & \multirow{3}{*}{$\begin{array}{c}\text { Operation } \\
\text { L amygd'y } \\
\text { R amygd'y } \\
\quad \text { (previous } \\
\text { bimedial } \\
\text { leucotomy) }\end{array}$} & \multirow{3}{*}{$\begin{array}{c}\text { Date } \\
\\
\text { 3 Jan. } 1967 \\
\text { 14 Mar. } 1967 \\
11 \text { May } 1961\end{array}$} & \multicolumn{3}{|c|}{ Clinical assessment } & \multirow{2}{*}{\multicolumn{2}{|c|}{$\begin{array}{c}\text { Length of follow-up } \\
\text { period } \\
(y r)(m t h)\end{array}$}} \\
\hline & & & \multirow{2}{*}{$\frac{\text { at } 4-6 \text { months }}{\text { Marked improvement }}$} & \multirow{2}{*}{$\frac{\text { at } 12 \text { months }}{\text { Marked improvement }}$} & \multirow{2}{*}{$\frac{\text { January, } 1973}{\text { Marked improvement }}$} & & \\
\hline & & & & & & 5 & 9 \\
\hline 2 & $\begin{array}{l}\text { L amygd'y } \\
\text { R amygd'y } \\
\text { Bimedial } \\
\quad \text { leucotomy }\end{array}$ & $\begin{array}{l}27 \text { Feb. } 1968 \\
12 \text { Mar. } 1968 \\
18 \text { Feb. } 1969\end{array}$ & No change & No change & $\begin{array}{l}\text { Slight improvement but } \\
\text { not attributed to } \\
\text { operations }\end{array}$ & 4 & 9 \\
\hline 3 & R amygd'y & 26 Mar. 1968 & Marked improvement & Marked improvement & Marked improvement & 4 & 9 \\
\hline 4 & R amygd'y & 16 Apr. 1968 & Slight improvement & Slight improvement & Slight improvement & 4 & 8 \\
\hline 5 & $\begin{array}{l}\text { L amygd'y } \\
\text { R amygd'y }\end{array}$ & $\begin{array}{r}7 \text { May } 1968 \\
28 \text { May } 1968\end{array}$ & No change & No change & No change & 4 & 7 \\
\hline 6 & $\begin{array}{l}\text { L amygd'y } \\
\text { (incomplete) }\end{array}$ & 18 June 1968 & Slight improvement & Slight improvement & No change & 4 & 6 \\
\hline 7 & $\begin{array}{l}\text { L amygd'y } \\
\text { R amygd'y }\end{array}$ & $\begin{array}{l}24 \text { June } 1968 \\
10 \text { Sept. } 1968\end{array}$ & No change & No change & No change & 4 & 3 \\
\hline 8 & $\begin{array}{l}\text { L amygd'y } \\
R \text { amygd'y }\end{array}$ & $\begin{array}{l}3 \text { Sept. } 1968 \\
22 \text { Oct. } 1968\end{array}$ & No change & No change & No change & 4 & 2 \\
\hline 9 & $\begin{array}{l}\text { L amygd'y } \\
R \text { amygd'y }\end{array}$ & 29 Oct. 1968 & Marked improvement & Marked improvement & Marked improvement & 4 & $\mathbf{0}$ \\
\hline 10 & $\begin{array}{l}\text { L amygd'y } \\
\mathbf{R} \text { amygd'y }\end{array}$ & $\begin{array}{r}5 \text { Nov. } 1968 \\
18 \text { Nov. } 1968\end{array}$ & No change & No change & No change & 4 & 1 \\
\hline 11 & $\begin{array}{l}\text { L amygd'y } \\
\text { R amygd'y }\end{array}$ & $\begin{array}{l}26 \text { Nov. } 1968 \\
17 \text { Nov. } 1968\end{array}$ & No change & No change & $\begin{array}{l}\text { Slight improvement but } \\
\text { not attributed to } \\
\text { operations }\end{array}$ & 4 & 0 \\
\hline 12 & $\begin{array}{l}\text { R amygd'y } \\
L \text { amygd'y }\end{array}$ & $\begin{array}{l}16 \text { Sept. } 1969 \\
14 \text { Oct. } 1969\end{array}$ & No change & No change & No change & 3 & 2 \\
\hline 13 & $\begin{array}{l}\text { R amygd'y } \\
L \text { amygd'y }\end{array}$ & $\begin{array}{r}4 \text { Nov. } 1969 \\
18 \text { Nov. } 1969\end{array}$ & No change & Slight improvement & Slight improvement & 3 & 1 \\
\hline 14 & $\begin{array}{l}\text { R amygd'y } \\
\text { L amygd'y }\end{array}$ & $\begin{array}{r}2 \text { Dec. } 1969 \\
16 \text { Dec. } 1969\end{array}$ & No change & No change & No change & 3 & 0 \\
\hline 15 & $\begin{array}{l}\text { R amygd'y } \\
\text { L amygd'y }\end{array}$ & $\begin{array}{r}17 \text { Feb. } 1970 \\
3 \text { Mar. } 1970\end{array}$ & No change & No change & No change & 2 & 9 \\
\hline 16 & $\begin{array}{l}\text { R amygd'y } \\
\text { L amygd'y }\end{array}$ & $\begin{array}{l}17 \text { Mar. } 1970 \\
26 \text { May } 1970\end{array}$ & Slight improvement & Slight improvement & No change & 2 & 7 \\
\hline 17 & $\begin{array}{l}\mathbf{R} \text { amygd'y } \\
\mathbf{L} \text { amygd'y }\end{array}$ & $\begin{array}{r}7 \text { July } 1970 \\
21 \text { July } 1970\end{array}$ & Marked improvement & Slight improvement & Slight improvement & 2 & 5 \\
\hline 18 & $\begin{array}{l}L \text { amygd'y } \\
R \text { amygd'y }\end{array}$ & $\begin{array}{r}1 \text { Sept. } 1970 \\
15 \text { Sept. } 1970\end{array}$ & Marked improvement & Marked improvement & Marked improvement & 2 & 3 \\
\hline
\end{tabular}

tive enough to permit pre- and postoperative recordings. In 11 cases recording and cerebral stimulation were carried out at operation. Depth electrography was also attempted, but in the first four cases technical difficulties prevented us from obtaining useful records. In the seven cases in which cerebral activity was recorded, the characteristic electrical activity of the amygdaloid nucleus described by Narabayashi et al. (1963) was found to be restricted to tissue with a depth of less than $1 \mathrm{~cm}$ (according to Baird et al. (1960) the human amygdaloid nucleus measures between $1.0 \mathrm{~cm}$ and $1.6 \mathrm{~cm}$ in its maximum height). In some cases the vertical coordinate of this activity varied by 0.5 to $1.0 \mathrm{~cm}$ from the calculated level of the target and in these cases the appearance of this activity was used as a guide to the final placement of the lesion.
The preoperative polygraphic recordings showed a disconcerting range of responses to the sound stimuli. Some patients were extremely anxious and showed little or no habituation to the full series. A few showed no response at all, even to the first sound.

The comparison of polygraphic recordings before and after operation did not reveal any consistent pattern. Four patients showed no appreciable change and of these one improved clinically. Three patients showed a reduction in autonomic activity after operation, a finding commonly interpreted as reflecting a reduction in arousal, and two of these improved clinically. In four cases autonomic activity consistent with increased arousal was seen after operation and one of these showed clinical improvement. 


\section{RESULTS}

The 18 patients were followed-up for periods ranging from two to nearly six years. The results are recorded briefly in Table 2 . The assessments were based on the examination of each patient, interviews with medical and nursing staff caring for those who were still inpatients, interviews with the closest family members of those who had become outpatients, evaluation of questionnaires completed by nursing and paramedical staff, and perusal of relevant medical and nursing records.

Nine patients $(50 \%)$ showed a diminution in aggressive behaviour for the first 12 months. Seven patients $(39 \%)$ showed persisting improvement throughout the follow-up period. Four of these cases showed a 'marked improvement': they exhibited less frequent and/or less intense aggression or self-mutilation to such an extent that their lives had changed dramatically and their immediate associates showed changed attitudes towards them. Three patients showed 'slight improvement': their aggression diminished but not to such an extent that their life situations were significantly altered. Two patients (cases 6 and 16) fell initially into the 'slight improvement' category but their behaviour regressed to its original state between 12 and 18 months after the operation. Two other subjects improved during the follow-up period but this improvement did not date from the operation and they are rated as failures. Seven cases showed no change in aggressive behaviour either immediately or during the period of review.

In no case was there any increase in aggressive behaviour after amygdaloidotomy. There has been no impairment of cognition or conation extending beyond the first postoperative week.

Three patients had preoperative sexual behaviour problems: case 18, a schizophrenic girl, masturbated excessively, case 14 made sexual assaults upon younger persons of either sex, and case 7 indulged in homosexual assaults. The sexual behaviour of the first two patients remained unaltered. The third patient has shown no homosexual activity during the follow-up period of over four years but he had aversion therapy for homosexuality just before amygdaloidotomy.
Four of our 13 non-epileptic patients had convulsions subsequent to amygdaloidotomy: case 16 interfered with his dressings and his left parietal incision became infected. Two months later he had a generalized convulsion and a right hemiparesis developed. Angiography did not display displacement of the cerebral vessels and it was presumed that the hemiparesis resulted from a cerebral thrombosis. Two and a half years later a mild hemiparesis persists but there have been no further convulsions and his EEG shows only minor non-specific abnormalities.

Case 2 had several focal convulsions confined to his right upper limb a week after left amygdaloidotomy. Because of the failure of bilateral amygdaloidotomy a bimedial leucotomy was performed 12 months later. After a further 10 months several convulsions were recorded. In the subsequent four years there have been no convulsions. No neurological abnormality is detectable. A generalized 4-7 Hz diffuse disturbance, more marked in the left side, persists in his EEG.

Case 14 is reported to have suffered from generalized convulsions beginning a year after amygdaloidotomy. Twelve months later there was no neurological abnormality and his EEG was within normal limits.

Case 10 had an isolated attack of status grand mal in association with a fever $\left(38.6^{\circ} \mathrm{C}\right)$ two and a half years after amygdaloidotomy. At review four years after the operation there is no neurological abnormality and his EEG is within normal limits.

\section{DISCUSSION}

The small number of patients in whom the operation appeared justified -18 over a period of three and a half years-made it difficult to design a properly controlled study. Turnbull (1969) has argued that the absence of matched control groups does not automatically invalidate such studies. It was felt that the patients in this present series provided their own controls: the behaviour disorder in each case was severe, longstanding, and unmodified by strenuous therapeutic efforts. It was assumed that spontaneous recovery was unlikely, although some doubts have been raised by the two cases (cases 
2 and 11) that improved three years after amygdaloidotomy.

Assessment of the results of the treatment of an episodic and unpredictable symptom such as aggressive behaviour can be a difficult task. Environmental factors frequently play a significant part in determining particular aggressive episodes and in some cases, as in case 9 who was given a life sentence, a particular aggressive act may result in profound environmental changes. Nevertheless, allowances can be made either for the amount of provocation or the lack of opportunity and it is felt that the assessments achieved in these patients are reasonably objective and accurate.

Aggressive behaviour can be directed towards other persons, towards objects such as furniture or towards oneself. All but two of our patients (cases 2 and 10) were aggressive to other persons; of these, seven $(44 \%)$ showed persistent improvement after amygdaloidotomy. Of the five subjects who had self-mutilating tendencies (Table 1) only one (case 1) showed persistent improvement. None of the five subjects who destroyed objects improved, although one (case 4) became less aggressive towards persons.

Self-mutilating and destructive tendencies were almost totally confined to the mentally retarded group. In this group, aggressive behaviour tended to be indiscriminate in contrast with the directed violence towards persons displayed by the non-retarded group. Vaernet and Madsen (1970) believe that the combination of amygdaloidotomy and leucotomy may be the most effective treatment for automutilative behaviour. Our experience with case 1 supports their observation.

Case 1 , a boy of 13 years at the time of his amygdaloidotomy, became severely retarded, hyperkinetic, self-destructive, and dangerously aggressive after a febrile illness at 18 months of age. At the age of six years he had a prefrontal leucotomy because it was felt that he might well kill himself through head-banging or cause serious injury to members of the nursing staff. This was ineffective. He was then safeguarded by a harness attached to the ceiling and floor of the dayroom, and attempts were made to control his behaviour with massive doses of psychotropic drugs and a number of courses of electroconvulsive therapy. After his amygdaloidotomy, five years ago, he showed a dramatic improve- $\bar{D}$ ment. It was possible to abandon his harness and, although occasionally aggressive, he has beenw able to join in ward activities and trainingo programmes. However, case 2 , who exhibited similar predominantly self-destructive behaviour, showed no response either to amygdaloidotomy or a subsequent bimedial leucotomy.

Of our eight severely retarded patients, only two showed sustained postoperative improvement. This supports the contention of Heimburger et al. (1966) that severely retarded $\overline{\bar{N}}$ patients are unlikely to respond to amygdaloidotomy. Two of our severely retarded patients (cases 6 and 16) showed good initial ${ }^{0}$ results followed by regression to their pre- $\vec{\circ}$ operative states at 15 months. Narabayashi and $\vec{\omega}$ Uno (1966) reported a fall-off in improvement $\stackrel{\omega}{\circ}$ rate from $85 \%$ to $68 \%$ during follow-up of their series for three to six and a half years.

Ten of our patients were of average or mildty. retarded intelligence. Of these, four exhibited schizophrenic features. Eighteen months after amygdaloidotomy, two of the schizophrenig을 were less physically violent. Six patients weweclassified as suffering from personality disorder, $;$; three of these showed sustained improvemeart postoperatively. All three were epileptic.

Our initial and sustained response rates $(50 \%$ and $39 \%$ respectively) are somewhat disappointing, though in line with the response rate of Narabayashi's adult group (31\% sustained im-⿳亠二口犬 provement). Several factors may be involved:

1. Each amygdaloid nucleus consists of $a \stackrel{\mathbb{2}}{2}$ complex cluster of nuclei with several different $\vec{\overrightarrow{ }}$ functions (Gloor, 1967). There are separate areas within the amygdala responsible for the initiation and the suppression of aggressive behaviour (Kaada, 1965). Present techniques allow the placement of a lesion with an average diameter? of about $0.8 \mathrm{~cm}$ but in view of the complexity of 3 these nuclei, topographic localization is likely to be imprecise.

2. The type of aggressive behaviour responsive $ᄋ$ to amygdaloidotomy needs definition. From our series, it would seem that self-mutilating be- 음 haviour and destructive behaviour may have a $N$ different pathophysiological significance from violence towards persons.

3. The coexistence of epilepsy may be im- $c$ portant. Four of our five epileptic patients $(80 \%)$ 
became less aggressive after amygdaloidotomy. One of these four patients (case 6) regressed after 12 months but it should be noted that the lesion was unilateral and was produced by the physical presence of the probe and not by freezing. As a group, the epileptics fared better than the others, although the difference is not statistically significant. Heimburger et al. (1966) found no correlation between the reduction in fit frequency and improvement in behaviour, in contrast with Narabayashi and Mizutani (1970) who found a parallel improvement in clinical seizures and behaviour. We did not observe the amelioration of epilepsy seen by Heimburger $e t$ al. (1966), by Narabayashi and Mizutani (1970), and by Mempel (1971): indeed, four of our patients, not known to be epileptic, suffered convulsions subsequent to operation.

Although there were many failures, the results reported are sufficiently encouraging to suggest that with more refined techniques the operation of bilateral amygdaloidotomy may have a valuable place in the treatment of certain types of violent behaviour.

\section{APPENDIX}

\section{Representative cases}

CASE 3 (M.36) Drop attacks commenced at the age of 13 years. These attacks occurred several times a week and were preceded by a brief sensation of fear. In 1967 they gave way to convulsive attacks. The patient had a number of complaints, including alcoholism, but his major source of distress was periodic irritability and aggressiveness. There was immediate relief of his irritability after a unilateral operation in March 1968. His convulsions seem unaltered. His life style in the subsequent four years has changed quite dramatically; he works as an accountant, lives in harmony with his cohabitee, and is better able to control his drinking.

CASE 9 (M.31) The patient spent his early life in orphanages and foster homes. He had his first generalized convulsion at the age of 18 years. From this time he spent most of his life in gaol for various crimes of violence. In 1962, under the influence of alcohol and methamphetamine, he killed his drinking companion by knifing him many times. After bilateral amygdaloidotomy in December 1968 his behaviour, as observed by his warders, has improved. He has had only two convulsions in the three years since operation. The psychiatric consultants to the penitentiary are convinced that he has lost his aggressive tendencies, and psychometric testing including the MMPI, the Edwards and Cattell tests, all indicate changes in his personality profile from gross abnormality to normality. $\mathrm{He}$ is now being considered for parole.

CASE 18 (F.29) This patient suffered a florid hebephrenic breakdown at the age of 15 years. For the seven years before operation she was in a psychiatric hospital where she proved to be a severe management problem. Impulsive violent outbursts were frequent and she would inflict great damage upon persons and property. Drugs and electroconvulsive therapy were ineffective. After bilateral amygdaloidotomy there were no physical attacks on patients or staff until a year postoperatively when she attacked a new member of the nursing staff. She is undoubtedly more placid. She remains thoughtdisordered and autistic but she is more cooperative since the operation.

\section{REFERENCES}

Baird, H. W., III, Spiegel, E. A., and Wycis, H. T. (1960). Studies in stereoencephalotomy. Confinia Neurologica, 20, 26-36.

Balasubramaniam, V., and Ramamurthi, B. (1968). Stereotaxic amygdalotomy. Proceedings of the Australasian Association of Neurologists, 5, 277-278.

Balasubramaniam, V., and Ramamurthi, B. (1970). Stereotaxic amygdalotomy in behaviour disorders. Confinia Neurologica, 32, 367-373.

Chatrian, G. E., and Chapman, W. P. (1960). Electrographic study of the amygdaloid region with implanted electrodes in patients with temporal lobe epilepsy. In Electrical Studies on the Unanesthetized Brain, pp. 351-373. Edited by E. R. Ramey and D. S. O'Doherty. Hoeber: New York.

Gloor, P. (1967). Discussion on brain mechanisms related to aggressive behavior. In Brain Function. Vol. V Aggression and Defence: Neural Mechanisms and Social Patterns. Edited by C. D. Clemente and D. B. Lindsley. University of California Press: Los Angeles.

Heath, R. G., Monroe, R. R., and Mickle, W. A. (1955). Stimulation of the amygdaloid nucleus in a schizophrenic patient. American Journal of Psychiatry, 111, 862-863.

Heimburger, R. F., Whitlock, C. C., and Kalsbeck, J. E. (1966). Stereotaxic amygdalotomy for epilepsy with aggressive behavior. Journal of the American Medical Association, 198, 741-745.

Kaada, B. (1965). Brain mechanisms related to aggressive behavior. UCLA Forum in Medical Sciences, no. 7, 95-133.

King, H. E. (1961). Psychological effects of excitation in the limbic system. In Electrical Stimulation of the Brain, pp. 477-486. Edited by D. E. Sheer. University of Texas Press: Austin, U.S.A.

Lader, M., and Wing, L. (1966). Physiological Measures, Sedative Drugs and Morbid Anxiety. Maudsley Monograph No. 14. Oxford University Press: London.

Mempel, E. (1971). Influence of partial amygdalectomy on the emotional disturbances and epileptic seizures. Neurologia i Neurochirurgia Polska, T.5(21), 81-86. 
Narabayashi, H., and Mizutani, T. (1970). Epileptic seizures and the stereotaxic amygdalotomy. Confinia Neurologica, 32, 289-297.

Narabayashi, H., Nagao, T., Saito, Y., Yoshida, M., and Nagahata, M. (1963). Stereotaxic amygdalotomy for behavior disorders. Archives of Neurology (Chic.), 9, 1-16.

Narabayashi, H., and Uno, M. (1966). Long range results of stereotaxic amygdalotomy for behavior disorders. Confinia Neurologica, 27, 168-171.

Sawa, M., Ueki, Y., Arita, M., and Harada, T. (1954). Preliminary report on the amygdaloidectomy on the psychotic patients, with interpretation of oral-emotional manifestation in schizophrenics. Folia Psychiatrica et Neurologica Japonica, 7, 309-329.

Schwab, R. S., Sweet, W. H., Mark, V. H., Kjellberg, R. N., and Ervin, F. R. (1965). Treatment of intractable temporal lobe epilepsy by stereotactic amygdala lesions. Transactions $(\mathbb{D}$ of the American Neurological Association, 90, 12-19.

Sweet, W. H., Ervin, F., and Mark, V. H. (1969). The relationship of violent behaviour to focal cerebral disease. In International Symposium on the Biology of Aggressive Behaviour, Milan, 1968, pp. 336-352. Edited by S. Garattini and E. B. Sigg. Excerpta Medica: Amsterdam.

Turnbull, F. (1969). Neurosurgery in the control of un- $\frac{\rho}{\partial}$ manageable affective reactions: a critical review. Clinical Neurosurgery, 16, 218-233.

Vaernet, K., and Madsen, A. (1970). Stereotaxic amygdalotomy and basofrontal tractotomy in psychotics with aggressive behaviour. Journal of Neurology, Neurosurgery and Psychiatry, 33, 858-863. 